\title{
Эпитаксиальные структуры InGaAs/InAIAs/AIAs для гетеробарьерных варакторов с низким током утечки
}

\author{
(C) Н.А. Малеев ${ }^{1,2}$, М.А. Бобров ${ }^{1}$, А.Г. Кузьменков ${ }^{1,3}$, \\ А.П. Васильев ${ }^{1,3}$, М.М. Кулагина ${ }^{1}$, С.Н. Малеев ${ }^{1}$, \\ С.А. Блохин ${ }^{1}$, В.Н. Неведомский ${ }^{1}$, В.М. Устинов ${ }^{1-3}$ \\ ${ }^{1}$ Физико-технический институт им. А.Ф. Иоффе РАН, Санкт-Петербург, \\ Россия \\ ${ }^{2}$ Санкт-Петербургский государственный электротехнический университет \\ „ЛЭТИ“, Санкт-Петербург, Россия \\ ${ }^{3}$ Научно-технологический центр микроэлектроники и субмикронных \\ гетероструктур РАН, Санкт-Петербург, Россия \\ E-mail: maleev@beam.ioffe.ru
}

\section{Поступило в Редакцию 30 мая 2018 г.}

\begin{abstract}
Качество гетерограниц и оптимальные условия эпитаксиального выращивания являются критически важными параметрами для получения низких токов утечки гетеробарьерных варакторов (ГБВ) в системе материалов InGaAs/InAlAs/AlAs. Выращенные методом молекулярно-пучковой эпитаксии трехбарьерные структуры ГБВ с примыкающими к барьерному слою InAlAs/AlAs/InAlAs дополнительными рассогласованными слоями InGaAs, испытывающими напряжение сжатия, при оптимальных режимах эпитаксии демонстрируют рекордно низкие уровни плотности тока утечки (не более $0.06 \mathrm{~A} / \mathrm{cm}^{2}$ при напряжении $5 \mathrm{~V}$ и температуре $85^{\circ} \mathrm{C}$ ) при относительно тонких AlAs-вставках (толщиной $2 \mathrm{~nm}$ ).
\end{abstract}

DOI: 10.21883/PJTF.2018.19.46678.17413

Создание компактных твердотельных источников для частотного диапазона $0.3-3 \mathrm{THz}$, работающих при комнатной температуре в непрерывном режиме, является актуальной научно-технической проблемой [1]. Квантово-каскадные лазеры, работающие в указанном диапазоне в качестве фундаментальных источников, требуют охлаждения до криогенных температур и не перекрывают диапазон частот ниже $1 \mathrm{THz}$ [2], а максимальная выходная мощность активных схем 
монолитных транзисторных усилителей частоты при продвижении в субмиллиметровый диапазон быстро убывает [3]. Умножители частоты, в которых используется генерация гармоник в нелинейных приборах, обеспечивают спектрально чистый сигнал, узкую линию генерации и более высокий уровень выходной мощности по сравнению с фундаментальными твердотельными источниками для рассматриваемого частотного диапазона. Базовым компонентом умножителей частоты субмиллиметрового диапазона являются диоды с барьером Шоттки, обеспечивающие минимальные паразитные параметры и позволяющие реализовать многокаскадные умножители с выходной частотой вблизи $1 \mathrm{THz}$ [4]. Эффективное умножение частоты с подавлением четных гармоник может быть реализовано на приборах с симметричной вольт-фарадной характеристикой (ВФХ), например, при встречном включении двух диодов с барьером Шоттки. Симметричными ВФХ и вольт-амперными характеристиками (BAX) обладают гетеробарьерные варакторы (ГБВ), предложенные в 1989 г. [5]. ГБВ на основе выращенных на подложках InP структур с несколькими нелегированными барьерными слоями InAlAs/AlAs/InAlAs, расположенными между модулирующими слоями InGaAs $n$-типа, успешно используются при создании умножителей частоты с уровнем непрерывной выходной мощности от сотен $\mathrm{mW}$ в частотном диапазоне около $100 \mathrm{GHz}$ до единиц $\mathrm{mW}$ на частотах вблизи $500 \mathrm{GHz}$ [6]. Однако в настоящий момент технология ГБВ не достигла требуемого уровня воспроизводимости, надежности и приемлемой стоимости изготовления для широкого практического внедрения. Одним из ключевых требований к структурам ГБВ является низкий уровень тока утечки при напряжениях, соответствующих максимальной амплитуде входного сигнала. В настоящей работе приведены результаты исследований по оптимизации конструкции и технологии молекулярно-пучковой эпитаксии (МПЭ) структур ГБВ, позволяющие добиться рекордно низких уровней тока утечки при одновременном повышении устойчивости технологии выращивания гетероструктур.

По результатам моделирования [7] оптимальная конструкция барьерного слоя ГБВ, обеспечивающая минимальные токи утечки, состоит из последовательности эпитаксиальных слоев $\operatorname{In}_{0.52} \mathrm{Al}_{0.48} \mathrm{As}(8 \mathrm{~nm}) / \mathrm{AlAs}$ $(3 \mathrm{~nm}) / \mathrm{In}_{0.52} \mathrm{Al}_{0.48} \mathrm{As}(8 \mathrm{~nm})$, окруженной слоями $\mathrm{In}_{0.53} \mathrm{Ga}_{0.47} \mathrm{As}$, однако в реальных приборных структурах для умножителей используются и другие варианты толщин слоев $\operatorname{In}_{0.52} \mathrm{Al}_{0.48} \mathrm{As}$, например $5 \mathrm{~nm}$ [8]. Проблемы при выращивании таких структур связаны с механическими

2 Письма в ЖТФ, 2018, том 44, вып. 19 
напряжениями, возникающими из-за наличия сильно рассогласованных по параметру кристаллической решетки слоев AlAs, что повышает риск формирования дефектов и дислокаций из-за накопления напряжений при последовательном выращивании нескольких барьерных слоев. Для преодоления данной проблемы была предложена конструкция трехбарьерных структур ГБВ с непосредственно примыкающими с двух сторон к гетеробарьеру $\operatorname{In}_{0.52} \mathrm{Al}_{0.48} \mathrm{As} / \mathrm{AlAs} / \mathrm{In}_{0.52} \mathrm{Al}_{0.48} \mathrm{As}$ тонкими рассогласованными слоями InGaAs, испытывающими напряжение сжатия, которые могут частично компенсировать механические напряжения, создаваемые AlAs-вставками [9]. В такой конструкции при толщине слоев $\mathrm{In}_{0.52} \mathrm{Al}_{0.48} \mathrm{As} 6 \mathrm{~nm}$ и толщине AlAs-вставок $2.5 \mathrm{~nm}$ была достигнута плотность тока утечки на уровне лучших опубликованных значений [8] для трехбарьерных структур ГБВ с толщиной AlAs-вставок $3 \mathrm{~nm}$.

В работе исследована возможность дальнейшего снижения токов утечки за счет оптимизации условий выращивания структур ГБВ методом МПЭ. Для улучшения морфологии поверхности при росте AlAs-вставок поток мышьяка снижался на 1/3 по сравнению со стандартным соотношением потоков элементов III и V групп (III/V $\sim 1: 3$ ), a при росте слоев InGaAs использовалось повышенное соотношение III/V. Скорости роста бинарных соединений отдельных слоев выбирались таким образом, чтобы точное согласование постоянных решетки слоев InAlAs и InGaAs с подложкой InP достигалось при еe температуре в процессе эпитаксии $\left(500-510^{\circ} \mathrm{C}\right)$. Используемый подход в сочетании с предложенной конструкцией барьерного слоя позволяет добиться высокого качества гетероинтерфейсов при увеличенной толщине AlAs-вставок. В качестве иллюстрации на рис. 1 представлены изображения в просвечивающем электронном микроскопе поперечного сечения барьерных слоев InAlAs/AlAs/InAlAs для двух структур: решеточно-согласованной, за исключением барьерных вставок AlAs c толщиной $1.5 \mathrm{~nm}$, и структуры с примыкающими к барьерному слою дополнительными тонкими рассогласованными слоями InGaAs и толщиной AlAs-вставки $2.5 \mathrm{~nm}$. В обоих случаях наблюдаются гладкие гетероинтерфейсы и отсутствуют выраженные структурные дефекты.

Несмотря на возможность получения качественных интерфейсов для барьерных слоев с AlAs-вставками толщиной 2.5-3 nm при использовании дополнительных напряженных слоев InGaAs, создаваемое механическое напряжение достаточно велико. Для исследования возможности

Письма в ЖТФ, 2018, том 44, вып. 19 

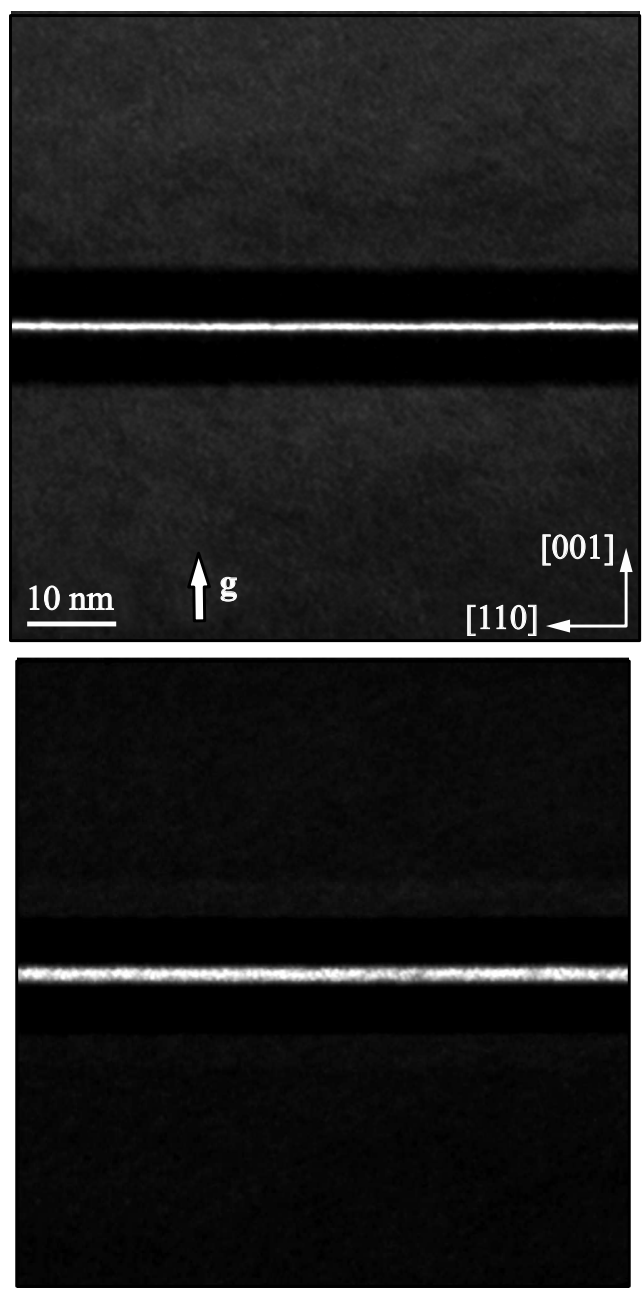

$a$

$b$

Рис. 1. Изображения в просвечивающем электронном микроскопе поперечного сечения барьерных слоев InAlAs/AlAs/InAlAs: решеточно-согласованной структуры с толщиной AlAs-вставки $1.5 \mathrm{~nm}(a)$ и структуры с примыкающими к барьерному слою тонкими рассогласованными слоями InGaAs и толщиной AlAs-вставки $2.5 \mathrm{~nm}(b)$.

2* Письма в ЖТФ, 2018, том 44, вып. 19 


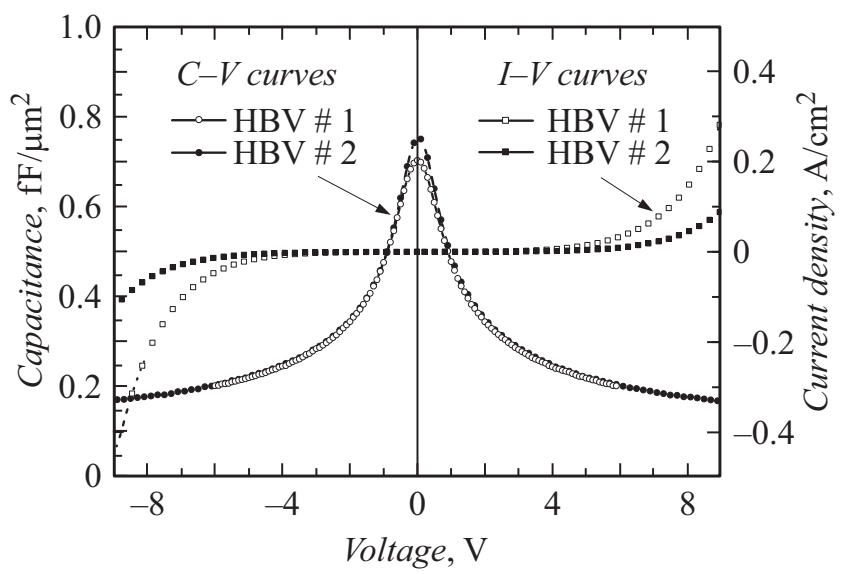

Рис. 2. Типичные вольт-фарадные и вольт-амперные характеристики тестовых ГБВ, изготовленных из двух выращенных гетероструктур, измеренные при комнатной температуре.

сохранения низких токов утечки при снижении толщины AlAs-вставок на установке МПЭ Riber Compact 21 в предварительно оптимизированных условиях были последовательно выращены две трехбарьерные структуры ГБВ с толщиной AlAs-вставок $2 \mathrm{~nm}$ : структура HBV\#1 с решеточно-согласованными, за исключением барьерных вставок AlAs, слоями и структура $\mathrm{HBV \# 2} \mathrm{с} \mathrm{дополнительными} \mathrm{тонкими} \mathrm{рассогласован-}$ ными слоями InGaAs с двух сторон от каждого барьерного слоя. Из выращенных гетероструктур были изготовлены тестовые ГБВ с размерами барьерного контакта $47 \times 47$ и $100 \times 100 \mu \mathrm{m}$, для которых проведены измерения $\mathrm{BAX}$ и $\mathrm{BФX} \mathrm{в} \mathrm{диапазоне} \mathrm{температур} \mathrm{от} 20$ до $95^{\circ} \mathrm{C}$.

На рис. 2 приведены типичные ВФХ и ВАХ тестовых ГБВ, изготовленных из двух выращенных гетероструктур, измеренные при комнатной температуре. Сравнение ВФХ показывает, что введение дополнительных слоев оказывает влияние на форму ВФХ только вблизи нулевого напряжения смещения, а в остальном диапазоне форма ВФХ совпадает, поскольку она определяется параметрами одинаковых для двух исследуемых структур модулирующих слоев InGaAs $n$-типа, разделяющих барьерные слои. ВАХ двух структур существенно различаются, при этом структура ГБВ с дополнительными тонкими рассо-

Письма в ЖТФ, 2018, том 44, вып. 19 


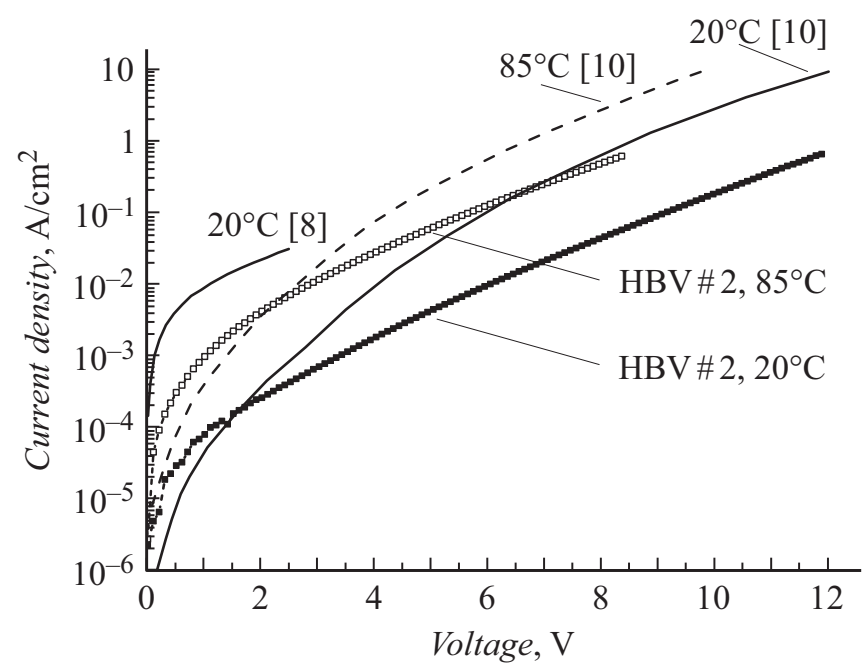

Рис. 3. Зависимости тока утечки от напряжения при комнатной температуре и температуре $85^{\circ} \mathrm{C}$ для исследуемой трехбарьерной структуры HBV\#2 и структур ГБВ с барьерными слоями $\operatorname{In}_{0.52} \mathrm{Al}_{0.48} \mathrm{As}(5 \mathrm{~nm}) / \mathrm{AlAs}(3 \mathrm{~nm}) /$ $\mathrm{In}_{0.52} \mathrm{Al}_{0.48} \mathrm{As}(5 \mathrm{~nm})$ : двухбарьерной (в пересчете на три барьера) [10] и трехбарьерной [8].

гласованными слоями InGaAs демонстрирует существенное снижение плотности тока утечки по сравнению со стандартной конструкцией (менее $0.1 \mathrm{~A} / \mathrm{cm}^{2}$ и более $0.3 \mathrm{~A} / \mathrm{cm}^{2}$ при напряжении смещения $9 \mathrm{~V}$ соответственно).

На рис. 3 приведены зависимости тока утечки от напряжения при комнатной температуре и температуре $85^{\circ} \mathrm{C}$, измеренные для исследуе-

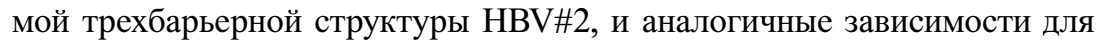
исследованной в работе [10] структуры ГБВ с двумя барьерными слоями $\mathrm{In}_{0.52} \mathrm{Al}_{0.48} \mathrm{As}(5 \mathrm{~nm}) / \mathrm{AlAs}(3 \mathrm{~nm}) / \mathrm{In}_{0.52} \mathrm{Al}_{0.48} \mathrm{As}(5 \mathrm{~nm})$, для которой были получены минимальные уровни плотности тока утечки. Для корректного сопоставления результатов приведенные в [10] ВАХ показаны в пересчете на три барьера. При использовании в умножителях в первую очередь важно обеспечить низкую утечку в диапазоне напряжений, близких к максимальной амплитуде входного умножаемого сигнала, и повышенных температур. Из сравнения приведенных данных следует,

Письма в ЖТФ, 2018, том 44, вып. 19 
что при напряжениях выше $2 \mathrm{~V}$ структура HBV\#2 имеет более низкие токи утечки как при комнатной, так и при повышенной температуре (при напряжении $5 \mathrm{~V}$ и температуре $85^{\circ} \mathrm{C}$ плотность тока утечки в 3-4 раза ниже - не более $0.06 \mathrm{~A} / \mathrm{cm}^{2}$ ). Следует отметить, что использованные в лучших образцах умножителей миллиметрового диапазона трехбарьерные структуры [8] имеют существенно более высокие плотности тока утечки, как показано на рис. 3, что можно связать с деградацией качества гетероинтерфейсов при накоплении внутренних структурных напряжений с ростом числа барьеров. По сравнению с трехбарьерными аналогами структура $\mathrm{HBV \# 2} \mathrm{обеспечивает} \mathrm{плотность}$ тока утечки при комнатной температуре практически на два порядка ниже. Для малых напряжений и низких температур в структурах ГБВ существенную роль играет туннельный ток утечки, а с ростом температуры доминирует термоэлектронная эмиссия, эффективность которой сильно зависит от высоты потенциального барьера. Измерения высоты потенциального барьера структур HBV\#1 и HBV\#2, выполненные по описанной в [10] методике, дают высоту потенциального барьера при малых напряжениях смещения на уровне $0.54-0.56 \mathrm{~V}$, что близко к опубликованным значениям для структур с толщиной AlAs-вставок $3 \mathrm{~nm}$ [10]. Можно предположить, что существенное снижение уровней токов утечки для выращенных структур ГБВ обеспечивается улучшением качества гетероинтерфейсов за счет оптимизации конструкции барьерного слоя и режимов эпитаксиального выращивания.

Исследования выполнены при поддержке Программы Президиума РАН № 9 „Терагерцевая оптоэлектроника и спинтроника“.

\section{Список литературы}

[1] Hesler J.L., Crowe T. High-power solid-state terahertz sources // SPIE Newsroom. 2015. DOI: 10.1117/2.1201506.005859

[2] Liang G., Liu T., Wang Q.J. // IEEE J. Select. Top. Quant. Electron. 2017. V. 23. P. 1200118.

[3] Zamora P.A., Mei G., Leong K.M.K.H., Lange M., Lee J., Yoshida W., Gorospe B.S., Padilla J.G., Deal W.R. // IEEE Microwave Wireless Compon. Lett. 2015. V. 25. N 9. P. 591-593.

[4] Maestrini A., Ward J.S., Gill J.J., Lee C., Thomas B., Lin R.H., Chattopadhyay G., Mehdi I. // IEEE Trans. Microwave Theory Technol. 2010. V. 58. N 7. P. 1925-1932.

Письма в ЖТФ, 2018, том 44, вып. 19 
[5] Kollberg E., Rydberg A. // Electron. Lett. 1989. V. 25. N 25. P. 1696-1698.

[6] Stake J., Malko A., Bryllert T., Vukusic J. // Proc. of the IEEE. 2017. V. 105. N 6. P. $1008-1019$.

[7] Fu Y., Stake J., Dillner L., Willander M., Kollberg E.L. // J. Appl. Phys. 1997. V. 82. N 11. P. 5568-5572.

[8] Malko A., Bryllert T., Vukusic J., Stake J. High efficiency and broad-band operation of monolithically integrated W-band HBV frequency tripler // 24th Int. Conf. on indium phosphide and related materials. Santa Barbara, 2012. P. 92-94.

[9] Малеев Н.А., Беляков В.А., Васильев А.П., Бобров М.А., Блохин С.А., Кулагина М.М., Кузьменков А.Г., Неведомский В.Н., Гусева Ю.А., Малеев С.Н., Ладенков И.В., Фефелова Е.Л., Фефелов А.Г., Устинов В.М. // ФТП. 2017. T. 51. B. 11. C. $1484-1488$.

[10] Dastjerdi M.H.T., Sanz-Velasco A., Vukusic J., Kollberg E.L., Sadeghi M., Stake J. // IEEE Electron Device Lett. 2011. V. 32. N 2. P. 140-142.

Письма в ЖТФ, 2018, том 44, вып. 19 